\title{
Microstructural, mechanical and electrochemical characterisation of biomaterial ASTM F745 cast by vacuum
}

\author{
R. W. Gregorutti*1 ${ }^{1}$, J. E. Grau ${ }^{1}$ and C. I. Elsner ${ }^{2,3}$
}

Countergravity low pressure casting (CLA) was performed to enhance the properties of ASTM F745 stainless steel (SS), which is usually used as biomaterial. The macro- and microstructures were compared with those obtained by the conventional process of investment casting (IC). The SS cast by CLA (SSCLA) exhibited a smaller size of solidification cell and finer dendritic microstructure. The average of its dendritic primary spacing was $110.4 \mu \mathrm{m}$, while for the same steel cast by IC (SSIC), it was $186.7 \mu \mathrm{m}$. The density of non-metallic inclusions $\delta_{1}$ in the SSCLA was $717 \mathrm{I} \mathrm{mm}^{-2}$, being the majority of them smaller than $1.5 \mu \mathrm{m}$. In the case of SSIC, $\delta$, was $852 \mathrm{I} \mathrm{mm}^{-2}$, with a size distribution of up to $8 \mu \mathrm{m}$. The SSCLA showed a higher breakdown potential than the SSIC, the values being 0.300 and $0.210 \mathrm{~V}$ (saturated calomel electrode) respectively, which means a higher resistance to suffer localised corrosion. Finely, the CLA process also allowed obtaining better mechanical properties.

Keywords: Biomaterials, Austenitic steel, Vacuum casting, Mechanical properties, Corrosion

\section{Introduction}

The ASTM F745 austenitic stainless steel (SS) is one of the alloys used to elaborate orthopaedic implants by casting due to its satisfactory mechanical and corrosion resistances and low cost with respect to Ti and CoCrMo alloys. ${ }^{1,2}$

These alloys must satisfy intrinsically related properties as biocompatibility, mechanical strength and principally corrosion resistance. The deterioration of the alloys used in surgical implants is the result of the combination of electrochemical and mechanical mechanisms. Medical devices implanted in the human body are exposed to the action of biological fluids containing water, salt, dissolved oxygen, bacteria, proteins and various ions such as chloride and hydroxide, which can eventually cause corrosion. Corrosion of metallic implants may affect the body tissue by the change in $\mathrm{pH}$ and the release of metallic ions. At the same time, the body movements and its own weight impose dynamic loads promoting mechanical fatigue and friction strain. Properties such as mechanical strength and corrosion resistance are directly related to the microstructure of the material, which is determined by the manufacturing process. In addition to machining and hot and cold forging, investment casting

\footnotetext{
${ }^{1}$ Laboratorio de Entrenamiento Multidisciplinario para la Investigación Tecnológica (LEMIT-CICPBA), Av. $52 \mathrm{~s} / \mathrm{n}$ e/121 y 122, La Plata B1900AYB, Argentina

${ }^{2}$ Centro de Investigación y Desarrollo en Tecnología de Pinturas (CIDEPINT-CICPBA-CONICET), Av. $52 \mathrm{~s} / \mathrm{n}$ e/121 y 122, La Plata B1900AYB, Argentina

${ }^{3}$ Facultad de Ingeniería, UNLP, Av. 1 esq. 47, La Plata B1900AYB, Argentina

*Corresponding author, email metalurgia@lemit.gov.ar
}

(IC) is one of the methods used to manufacture load bearing components as knee and hip joint prostheses. The main variables of the casting process are the temperatures of the melt and the shell mould, which define the microstructure of the cast metal in terms of the present phases, grain size and micro- and macrosegregation. Another feature that should be considered is the amount and size of non-metallic inclusions formed, especially by the reaction of the melt with the oxygen of the air, during the different steps of the casting process. In previous works, it has been reported that failures caused by mechanical fatigue, corrosion or combination of both mostly originated from the presence of non-metallic inclusions. ${ }^{3-7}$ The harmful effect of these particles lies in the fact that, eventually, they act as source of nucleation and propagation of fissures and also can increase the susceptibility to localised corrosion. According to these considerations, it should be relevant to improve the metallurgical quality of the biomaterials with the aim of minimising the risk of failure. In this frame, the present work evaluates the microstructure, mechanical properties and susceptibility to localised corrosion of the biomaterial ASTM F745 SS cast in vacuum by means of the countergravity low pressure casting (CLA) process $^{8}$ (hereafter, SSCLA) and compares the results with those obtained for the same steel cast by the conventional IC process (hereafter, SSIC).

\section{Experimental}

The chemical composition of the SS analysed in the present work was as follows: $\mathrm{Fe}-0 \cdot 042 \mathrm{C}-17 \cdot 93 \mathrm{Cr}-$ 
$12 \cdot 47 \mathrm{Ni}-2 \cdot 04 \mathrm{Mo}-0 \cdot 47 \mathrm{Si}-0 \cdot 9 \mathrm{Mn} \quad(\mathrm{wt}-\%)$. Melting was performed using an induction furnace of $30 \mathrm{~kg}$ capacity. As usual practice of the IC process, the shell mould was heated up to $800^{\circ} \mathrm{C}$ to increase its permeability and reduce the thermal gradient of cooling, in order to improve castability. Subsequently, it was filled by pouring the melt from a ladle, favoured by gravity. On the other hand, the CLA process was carried out by placing the preheated $\left(100^{\circ} \mathrm{C}\right.$ to eliminate humidity $)$ shell mould in a casting chamber connected to a vacuum pump. In this process, the shell mould was filled by suction, directly from the induction furnace, due to the pressure difference caused by vacuum. The main parameters of both processes are reported in Table 1 .

The solidification structures obtained in both casting methods were evaluated in Charnley femoral prosthesis, with the macro- and microstructures being revealed with Beraha's etching. ${ }^{9}$ Scanning electron microscopy was used for metallographic characterisation, while microsegregation was measured by energy dispersive X-ray spectroscopy (EDS). The density and size of nonmetallic inclusions as well as dendritic arm spacing were measured by means of a Buehler quantitative image analyser with Omnimet Enterprise software. Solution annealing heat treatment at $1080^{\circ} \mathrm{C}$ was performed to dissolve $\delta$-ferrite and carbides. Mechanical properties were evaluated through tensile tests on samples of $6.25 \mathrm{~mm}$ diameter (Standard ASTM E8) using an Instron machine of 15 ton capacity. The susceptibility to localised corrosion was evaluated through cyclic polarisation test, following ASTM F2129-04. The corrosion cell was assembled with the test material as working electrode, a saturated calomel electrode (SCE) as reference and a Pt electrode as auxiliary. Human environment was simulated with aqueous solution of $0 \cdot 9 \mathrm{wt}-\% \mathrm{NaCl}$ at $37^{\circ} \mathrm{C}$ and $\mathrm{pH}$ between $7 \cdot 1$ and $7 \cdot 4$. The solution was deaerated by bubbling $\mathrm{N}_{2}$ during the tests. Tests were performed using an EG\&G potentiostat/ galvanostat model 273A. The potential sweep was performed between $-0 \cdot 1 \mathrm{~V}$ (open circuit potential) and $0 \cdot 3 \mathrm{~V}(\mathrm{SCE})$ at a scan rate of $0 \cdot 167 \mathrm{mV} \mathrm{s}^{-1}$. Before the potential scan, the samples were kept at open circuit potential for $1 \mathrm{~h}$, and after that stabilisation period, the initial corrosion potential $E_{\text {corr }}$ was determined.

\section{Results and discussion}

\section{Metallographic analysis}

The macrostructures of the femoral prosthesis obtained by both casting methods are shown in Fig. 1, which illustrates that the solidification cell size of SSCLA was significantly smaller than that of SSIC.

The smaller solidification cell in the SSCLA can be attributed to the different conditions leading to nucleation in each process. The lower shell mould temperature in the vacuum process promoted a greater cooling rate, which led to the increase in thermal undercooling $\Delta T_{\mathrm{T}}$ in

Table 1 Parameters of IC and CLA processes

\begin{tabular}{lcr}
\hline Parameter & IC & CLA \\
\hline Temperature of melt $/{ }^{\circ} \mathrm{C}$ & 1600 & 1600 \\
Temperature of shell mould $/{ }^{\circ} \mathrm{C}$ & 800 & 100 \\
$\Delta P / \mathrm{mmHg}$ & $\ldots$ & 40 \\
Suction time/s & $\ldots$ & 15 \\
\hline
\end{tabular}

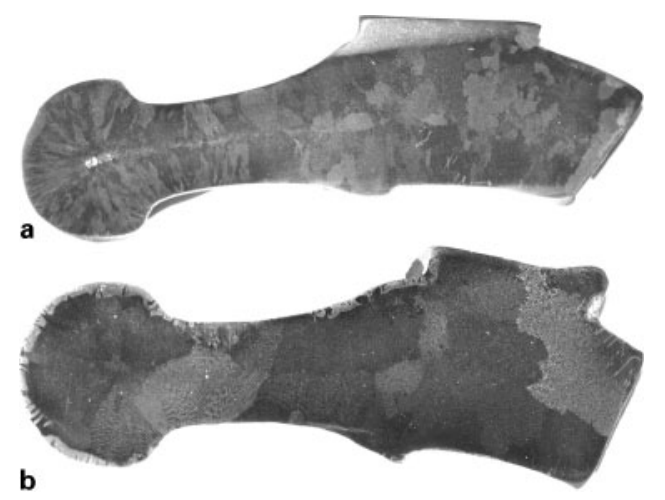

a SSCLA; $b$ SSIC

1 Macrostructure of femoral prosthesis

the melt defined as $\Delta T_{\mathrm{T}}=T_{\mathrm{e}}-T^{*}$, where $T_{\mathrm{e}}$ is the equilibrium melting temperature, and $T^{*}$ is the temperature of the undercooled liquid. According to the fundamentals of solidification, the higher the undercooling between the melting point and the temperature of the melt, the smaller will be the critical size required for a cluster to constitute a nucleus, increasing in this form the nucleation rate during solidification.

The 'as cast' microstructure obtained in both processes consisted of dendrites of austenite with the development of secondary branches, as shown in Fig. 2.

The dendritic microstructure of the SSCLA was thinner than that of SSIC, with smaller primary and secondary dendritic arm spacings. This behaviour can also be ascribed to the higher cooling rate induced in the vacuum process.

Primary and secondary dendritic arm spacings depend inversely on the product of the thermal gradient $G$ and the growth rate $V$, being these parameters directly related to the cooling rate. ${ }^{10,11}$ The greater the cooling rate, the higher $G$ and $V$ and, accordingly, the lower the dendritic arm spacing. Primary and secondary dendritic spacings were estimated by considering the average of 15 measurements in three different areas, the results being quoted in Table 2.

Figure 2 also shows the formation of $\delta$-ferrite in the interdendritic spaces as a consequence of the microsegregation of the alloying elements during solidification.

The influence of the casting methods on the microsegregation of the alloying elements present in the SSCLA and SSIC was evaluated by means of EDS, the results being recorded in Table 3 .

The SSIC shows a higher concentration of $\mathrm{Cr}$ and Mo in the interdendritic spaces as a consequence of their partition coefficient $k<1$, which promotes the direct segregation towards the last to freeze liquid. In contrast, the $\mathrm{Ni}$ concentration was higher in the body of the dendrite because this element segregates inversely as a consequence of its partition coefficient $k>1$. On the other hand, it was observed that the concentrations of $\mathrm{Cr}$, Mo and $\mathrm{Ni}$ between the dendrite body and the interdendritic spaces in the SSCLA do not differ significantly. Although EDS analysis is semiquantitative, from these results, it could be inferred that the vacuum process could lower the trend to microsegregation, promoting a more homogeneous material. The lower microsegregation of alloying elements in this process could be related to the greater growth rate, which would lead to a faster advance of the solid/liquid 

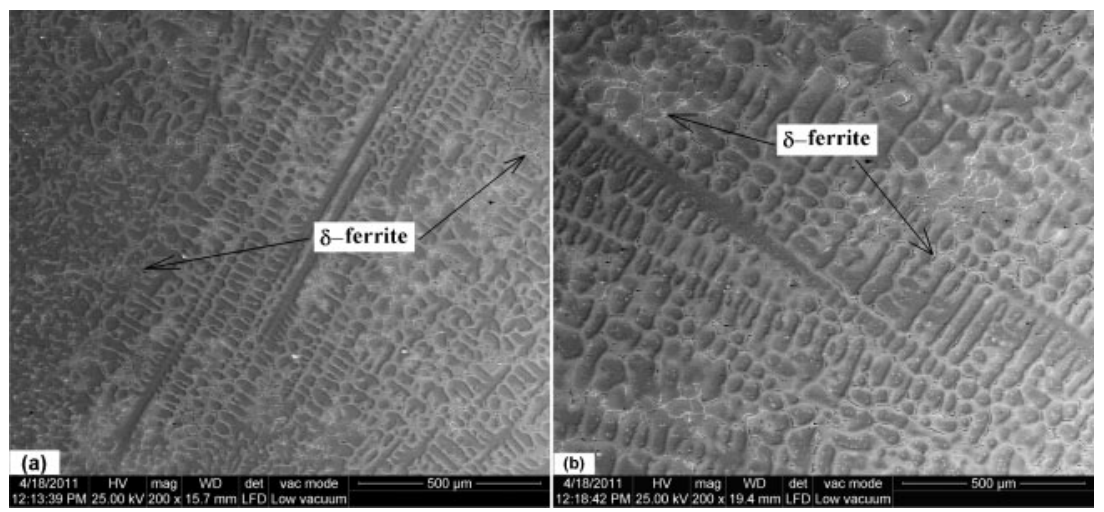

a SSCLA; $b$ SSIC

2 As cast microstructures

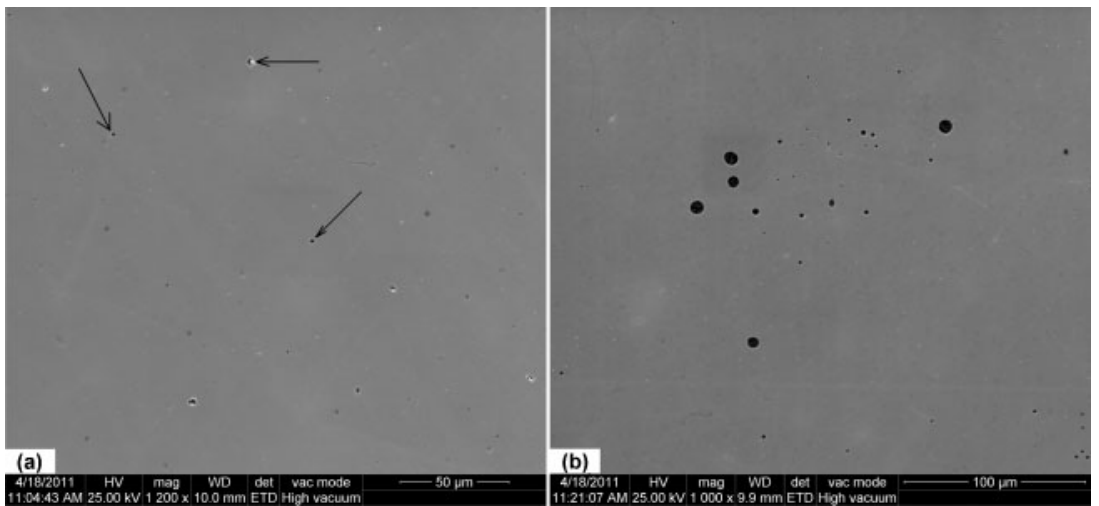

a SSCLA; $b$ SSIC

3 Non-metallic inclusions

interface with regard to the escape of solute atoms into the liquid.

In the case of the SSIC, the higher microsegregation of $\mathrm{Cr}$ and Mo leads to the increase in the formation of $\delta$ ferrite in the interdendritic regions during solidification, as shown in Fig. 2. The presence of $\delta$-ferrite requires a heat treatment of solution annealing, since it may be detrimental to corrosion resistance and mechanical properties. In addition, its ferromagnetic characteristic can be harmful when studied with, for example, magnetic resonance imaging. ${ }^{12,13}$

The other important factors to be considered in the microstructure are the amount and size of non-metallic

Table 2 Average values of primary and secondary dendritic arm spacings

\begin{tabular}{lll}
\hline $\begin{array}{l}\text { Casting } \\
\text { process }\end{array}$ & $\begin{array}{l}\text { Dendritic } \\
\text { primary } \\
\text { spacing } / \mu \mathrm{m}\end{array}$ & $\begin{array}{l}\text { Dendritic } \\
\text { secondary } \\
\text { spacing/ } \mu \mathrm{m}\end{array}$ \\
\hline IC & $186 \cdot 7$ & $46 \cdot 1$ \\
CLA & $110 \cdot 4$ & $34 \cdot 1$ \\
\hline
\end{tabular}

inclusions due to its influence on the mechanical and electrochemical properties of the biomaterial. The micrographs in Fig. 3 show spherical particles, which, according to ASTM E45, correspond to oxide type inclusions. In this case, it can be assumed that the oxide inclusions were formed from the interaction of the different alloying elements of steel with the oxygen dissolved in the melt during the casting practice.

Figure 3 also shows that the sizes of non-metallic inclusions in the SSCLA were significantly smaller with respect to the SSIC. The histograms in Fig. 4, obtained from the analysis performed in 20 different fields of each sample, revealed that the distribution of inclusion size in the SSCLA was up to $3.5 \mu \mathrm{m}$, the majority of them being smaller than $1.5 \mu \mathrm{m}$. On the other hand, the SSIC showed a broader size distribution up to $8 \mu \mathrm{m}$ with the majority of them in the range between 1 and $3 \mu \mathrm{m}$.

The other important feature that differentiates the two casting processes is the density of non-metallic inclusions $\delta_{\mathrm{I}}$ present in the SS. Particle counting revealed that $\delta_{\mathrm{I}}$ was $717 \mathrm{I} \mathrm{mm}^{-2}$ for the SSCLA and $852 \mathrm{I} \mathrm{mm}^{-2}$ for the SSIC.

Table 3 Concentration of alloying elements obtained by EDS (wt-\%)

\begin{tabular}{|c|c|c|c|c|}
\hline \multirow[b]{2}{*}{ Element } & \multicolumn{2}{|l|}{ SSIC } & \multicolumn{2}{|l|}{ SSCLA } \\
\hline & Dendrite body & Interdendritic region & Dendrite body & Interdendritic region \\
\hline $\mathrm{Cr}$ & $16 \cdot 71$ & $22 \cdot 52$ & $17 \cdot 01$ & $18 \cdot 84$ \\
\hline Mo & $1 \cdot 19$ & 3.98 & $1 \cdot 60$ & $2 \cdot 54$ \\
\hline $\mathrm{Ni}$ & $11 \cdot 41$ & $9 \cdot 66$ & $13 \cdot 07$ & $12 \cdot 23$ \\
\hline
\end{tabular}




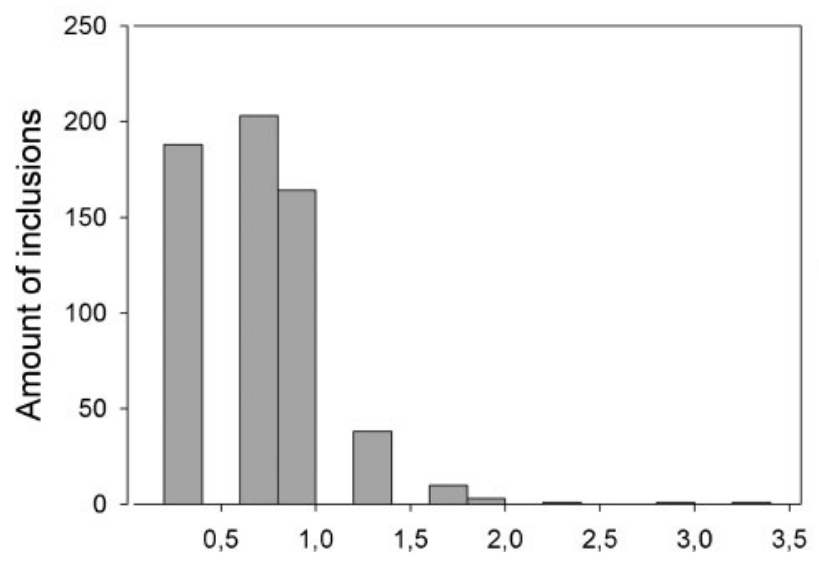

(a)

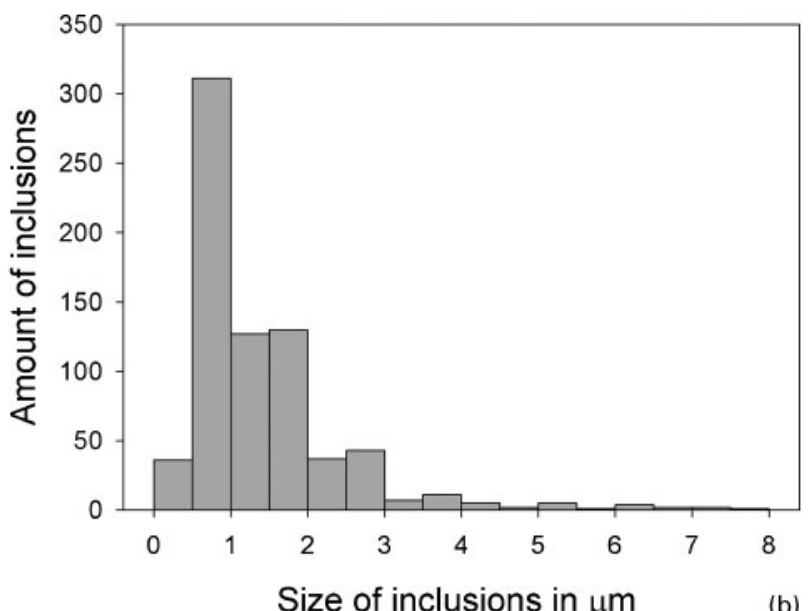

(b)

a SSCLA; $b$ SSIC

4 Histograms of non-metallic inclusions

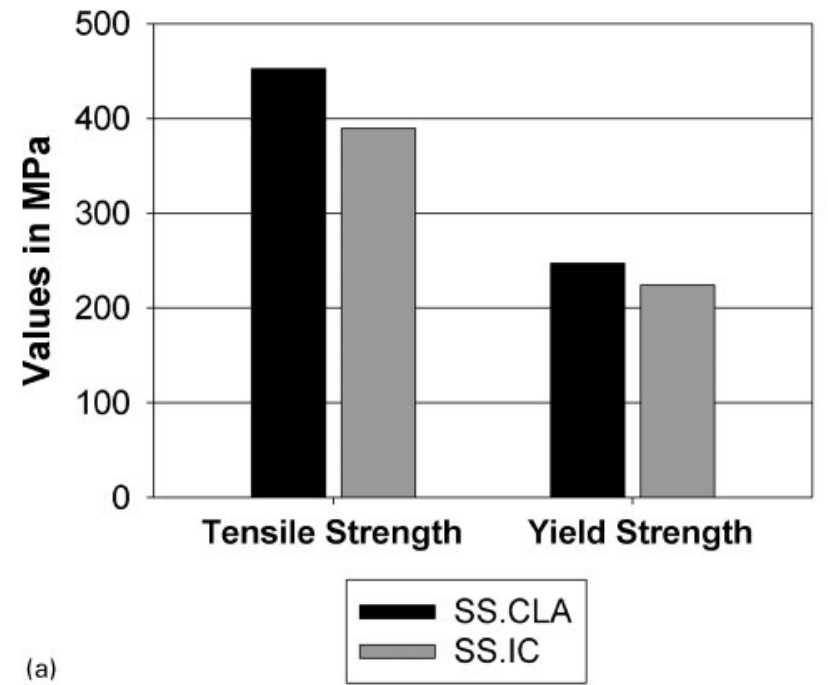

$a$ tensile and yield strengths; $b$ elongation

5 Mechanical properties

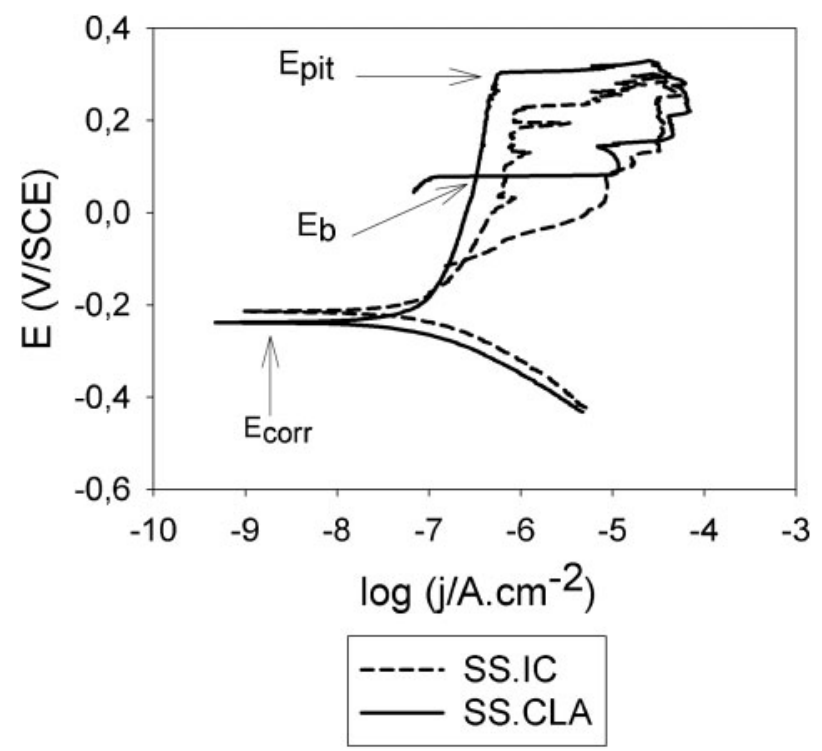

6 Potentiodynamic curves

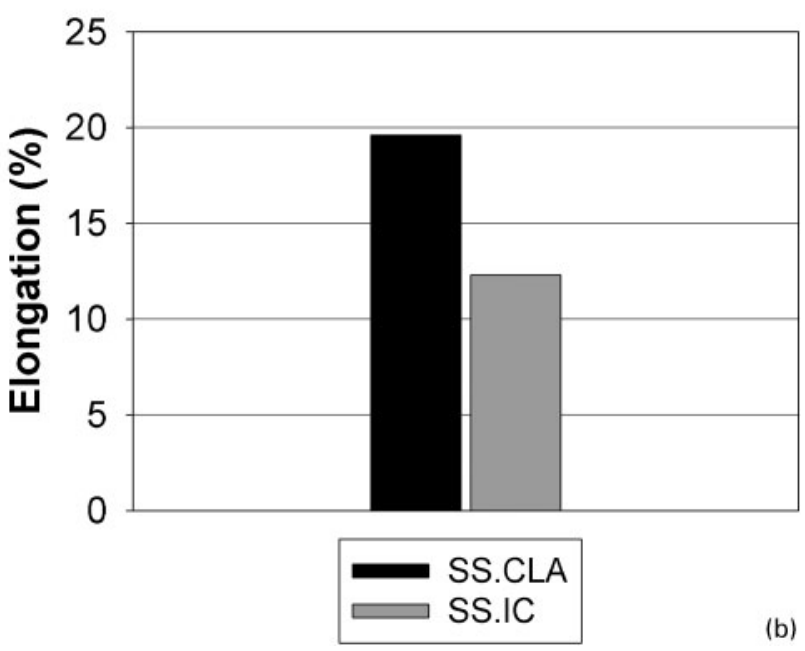

The higher level of non-metallic inclusion in the SSIC can be related to the longer interaction of the melt with oxygen during this casting process. The dissolution of oxygen in steel occurs during the melting step in furnace, during the transfer of the melt from furnace to the ladle and finally when the melt is poured into the shell mould. In the case of the CLA process, the interaction with oxygen is minimised since the melt is directly sucked up from the furnace into the shell mould, reducing in this form the dissolution of this element into steel.

\section{Mechanical properties}

The results of the tensile test performed in solution annealed samples of the SS obtained in both casting processes are illustrated in Fig. 5.

The SSCLA showed a considerable increment in tensile and yield strengths and elongation with respect to SSIC. The improvement of the mechanical properties in the steel cast in vacuum can be related to its smaller size of solidification cell and its lower density and size of non-metallic inclusions.

\section{Susceptibility to localised corrosion}

The relative susceptibility to localised corrosion behaviour of the SSCLA and the SSIC was evaluated by 


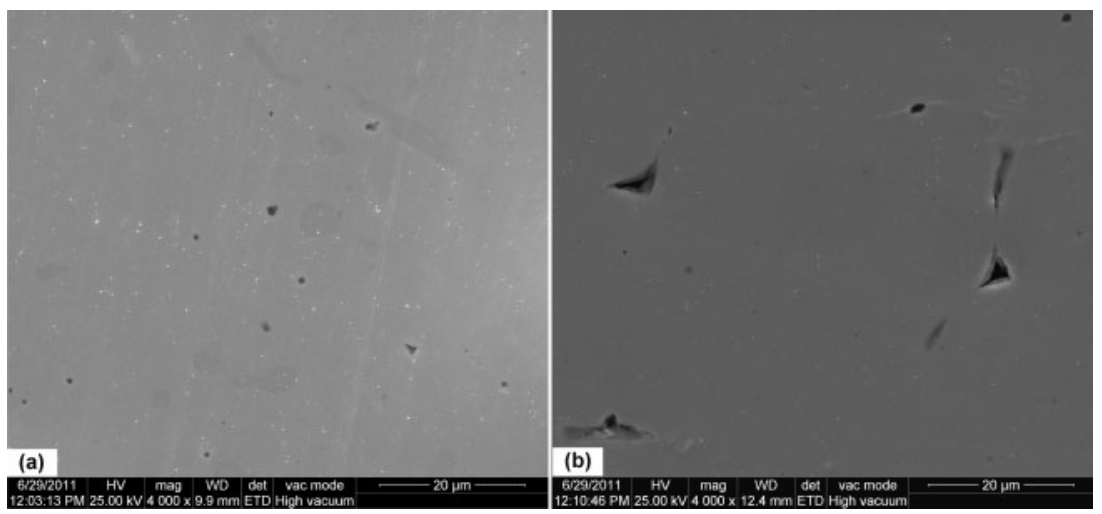

a SSCLA; $b$ SSIC

7 Pitting development

Table 4 Electrochemical parameters obtained from potentiodynamic tests

\begin{tabular}{lllllll}
\hline & $E_{\text {corr }} / \mathrm{N}(\mathrm{SCE})$ & $E_{\mathrm{pit}} / \mathrm{N}(\mathrm{SCE})$ & $E_{\mathrm{pit}}-E_{\mathrm{corr}} / \mathrm{N}$ & $E_{\mathrm{b}} / \mathrm{V}(\mathrm{SCE})$ & $E_{\mathrm{pit}}-E_{\mathrm{b}} / \mathrm{V}$ & $j_{\mathrm{corr}} / \mu \mathrm{A} \mathrm{cm} \mathrm{cm}^{-2}$ \\
\hline SSIC & -0.214 & 0.215 & 0.429 & -0.105 & 0.320 & 0.120 \\
SSCLA & -0.237 & 0.300 & 0.537 & 0.080 & 0.220 & 0.100 \\
\hline
\end{tabular}

means of cyclic polarisation tests. The main features of this technique are the evaluation of the breakdown potential $E_{\mathrm{pit}}$ and the protection potential $E_{\mathrm{b}}$. The $E_{\mathrm{pit}}$ is the polarisation level at which the anodic current increases considerably with the applied potential, and $E_{\mathrm{b}}$ is the potential at which the hysteresis loop is completed upon reverse polarisation scan. Those parameters are related with the material's susceptibility to suffer localised corrosion and its capacity to its development respectively. The more electropositive both values are, the less likely that localised corrosion occurs. At the same time, the lesser is the difference $\left(E_{\mathrm{pit}}-E_{\mathrm{corr}}\right)$, the more prone the material is to suffer localised corrosion. On the other hand, the corrosion current density was determined by extrapolation of the anodic/cathodic $j-E$ curve to the corrosion potential. The parameters recorded from the potentiodynamic curves, corresponding to solution annealed samples, are shown in Fig. 6.

This plot shows that both materials had similar $E_{\text {corr }}$ and $j_{\text {corr }}$ values. However, their susceptibility to localised corrosion was quite different. The $E_{\text {pit }}$ for the SSCLA was more electropositive than that corresponding to the SSIC. At the same time, its hysteresis loop was completed at $E_{\mathrm{b}}$ potentials closer than the corresponding $E_{\mathrm{pit}}$, the difference $\left(E_{\mathrm{pit}}-E_{\mathrm{b}}\right)$ being significantly minor. This behaviour would indicate that the SSCLA not only has a higher resistance to localised corrosion but also has a higher tendency to repassivate. In addition, the anodic polarisation scan for the SSIC exhibited higher current fluctuation in the potential range upon $E_{\text {pit }}$, revealing that this material has a higher susceptibility to break down the passive film. Figure 7 shows the greater development of localised corrosion in this steel, in which large pits are observed, while the attack in the SSCLA seems to be incipient.

The higher susceptibility to localised corrosion observed in SSIC could be related to its greater level of non-metallic inclusions, which eventually act as source of pit nucleation. These results are in agreement with previous works, which analysed the influence of the type and density of non-metallic inclusions in a ferritic
SS by means of electrochemical noise analysis. ${ }^{14}$ At the same time, several studies reported the critical role of the inclusions on the pitting corrosion of biomedical implants. ${ }^{5,15-17}$

The electrochemical parameters obtained from the potentiodynamic curves are summarised in Table 4.

\section{Conclusions}

Biomaterial ASTM F745 cast in vacuum by means of CLA process exhibited better mechanical properties and higher resistance to suffer localised corrosion, in media that simulate the human environment, compared to SSIC. The improvement of these properties can be related to the higher metallurgical quality achieved in the CLA process, since a macrostructure with smaller size of solidification cell and a finer dendritic microstructure was obtained. ASTM F745 cast in vacuum also showed a lesser tendency to microsegregate $\mathrm{Cr}$ and $\mathrm{Mo}$ in the interdendritic regions of the 'as cast' microstructure, which could reduce the formation of $\delta$-ferrite during solidification. Finally, the CLA process reduces the interaction of the melt with oxygen, obtaining steel with lower amount and size of non-metallic inclusions.

\section{Acknowledgements}

The authors thank the Comisión de Investigaciones Científicas de la Provincia de Buenos Aires (CICPBA), the Consejo Nacional de Investigaciones Científicas y Técnicas (CONICET) and the Universidad Nacional de La Plata of Argentina for the financial support to carry out the present research paper.

\section{References}

1. 'Specification for 18 chromium-12.5nickel-2.5molybdenum stainless steel manufacturing and related processes' ASTM F745-07, Section 13, 302-304, ASTM International, Baltimore, MD, USA, 2007.

2. J. B. Brunski: in 'Biomaterials science - an introduction to materials in medicine', (ed. B. D. Ratner et al.), 2nd edn, 137153; 2004, San Diego, CA, Elsevier Academic Press.

3. S. H. Teoh: Int. J. Fatigue, 2000, 22, 825-837. 
4. K. V. Sudhakar: Eng. Fail. Anal., 2005, 12, 249-256.

5. M. Sivakumar, U. Kamachi Mudali and S. Rajeswari: J. Mater. Sci. Lett., 1995, 14, 148-151.

6. E. Proverbio and L. M. Bonaccorsi: J. Fail. Anal. Prev., 2001, 4, 33-38.

7. C. Demian, V. A. Şerban, A. Răduţă, I. Vida-Simiti, R. Prejbeanu and C. Locovei: J. Optoelectron. Biomed. Mater., 2009, 1, 172-179.

8. ASM International: 'Metals handbook', 9th edn, Vol. 15, 'Casting', 696-700; 1988, Materials Park, OH, ASM International.

9. ASM International: 'Metals handbook', 9th edn, Vol. 9, 'Metallography and microstructures', 141; 1988, Materials Park, $\mathrm{OH}$, ASM International.

10. W. Kurz and D. J. Fisher: 'Fundamentals of solidification', 3rd edn, 63-92; 1992, Aedermannsdorf, Trans Tech Publications.
11. M. C. Flemings: 'Solidification processing', 'Materials science and engineering series', 146-154; 1974, New York, McGraw-Hill, Inc.

12. M. Sawyer-Glover and F. G. Shellock: J. Magn. Reson. Imaging, 2000, 12, 92-106.

13. H. Matsuura, T. Inoue, H. Konno, M. Sasaki, K. Ogasawara and A. Ogawa: J. Neurosurg., 2002, 97, 1472-1475.

14. H. Y. Ha, C. J. Park and H. S. Kwon: Corros. Sci., 2007, 49, 12661275.

15. G. Manivasagam, D. Dhinasekaran and A. Rajamanickam: Corros. Sci., 2010, 2, 40-54.

16. U. Kamachi Mudali, T. M. Sridhar and B. Raj: Sadhana, 2003, 28, 601-637.

17. K. Zhang, J. Zou, T. Grosdidier, C. Dong and D. Yang: Surf. Coat. Technol., 2006, 201, 1393-1400. 